\title{
A Strip-Coupler for Dynamic Capacitive Wireless Power Transfer
}

\author{
Chen, Xu; Yu, Shengbao; Zhang, Zhe
}

Published in:

Proceedings of 45th Annual Conference of the IEEE Industrial Electronics Society

Link to article, DOI:

10.1109/IECON.2019.8926917

Publication date:

2020

Document Version

Peer reviewed version

Link back to DTU Orbit

Citation (APA):

Chen, X., Yu, S., \& Zhang, Z. (2020). A Strip-Coupler for Dynamic Capacitive Wireless Power Transfer. In Proceedings of 45th Annual Conference of the IEEE Industrial Electronics Society IEEE.

https://doi.org/10.1109/IECON.2019.8926917

\section{General rights}

Copyright and moral rights for the publications made accessible in the public portal are retained by the authors and/or other copyright owners and it is a condition of accessing publications that users recognise and abide by the legal requirements associated with these rights.

- Users may download and print one copy of any publication from the public portal for the purpose of private study or research.

- You may not further distribute the material or use it for any profit-making activity or commercial gain

- You may freely distribute the URL identifying the publication in the public portal

If you believe that this document breaches copyright please contact us providing details, and we will remove access to the work immediately and investigate your claim. 


\title{
A Strip-Coupler for Dynamic Capacitive Wireless Power Transfer
}

\author{
$\mathrm{Xu}$ Chen ${ }^{1,2}$, Shengbao $\mathrm{Yu}^{1}$ and Zhe Zhang ${ }^{2}$ \\ ${ }^{1}$ College of Instrumentation and Electrical Engineering, Jilin University, ChangChun, China \\ ${ }^{2}$ Department of Electrical Engineering, Technical University of Denmark \\ chenxu16@mails.jlu.edu.cn,xuchen@elektro.dtu.dk, yushengbao@jlu.edu.cn, zz@elektro.dtu.dk
}

\begin{abstract}
Dynamic wireless power transfer is an effective way to mitigate the range anxiety of electric vehicles. This paper presents a strip-coupler for dynamic capacitive wireless power transfer application with reduced cost and increased misalignment tolerance. The structure of the proposed stripcoupler and the concept of strip-coupler based dynamic wireless power system is explained. A detailed comparison between prior-art coupler and the proposed strip-coupler in terms of cost, electric fields and misalignment performance is conducted. The power transfer ability of the strip coupler is also calculated.
\end{abstract}

Keywords-dynamic wireless power transfer, capacitive power transfer, parallel plate capacitor, misalignment

\section{INTRODUCTION}

Pushing by the advances in battery technology and the pressure of reducing greenhouse gas emissions, such as $\mathrm{CO}_{2}$, the electric vehicles (EV) are viewed as an attractive candidate to replace the conventional internal combustion vehicles[1]. However, electric vehicles based on the state-of-art battery technology is still not enough to keep the same mileage as conventional vehicles. Dynamic wireless power transfer is capable of powering electric vehicles while they are moving on the road. With dynamic wireless power transfer technology, the range anxiety of electric vehicles can be mitigated before the breakthrough in battery technology appears. The dynamic wireless power transfer can also be used to power Automated Guided Vehicles (AGV) in modern factory and logistic sorting system[2].

Because of these advantages and future prospects, the dynamic wireless power transfer has been widely researched worldwide. Representative research teams including Auckland University [3], the Oak Ridge National Laboratory (ORNL) [4] and KAIST [5] in South Korea. They are all based on inductive coupling (with coil and magnetic field). Up to five generations of on-line electric vehicle (OLEV, which is the dynamic wireless power transfer system named by KAIST) has been developed for demonstration. However, the inductive coupled dynamic wireless transfer technology relies on the magnetic cores buried underground to increase the coupling with the pick-up coil on the vehicle, which is, however, both expensive and fragile[6]. Based on the economic analysis of the dynamic charging electric vehicle, the reconstruction cost is also a non-negligible factor if these coils and magnetic cores are to be buried under the existing roads.

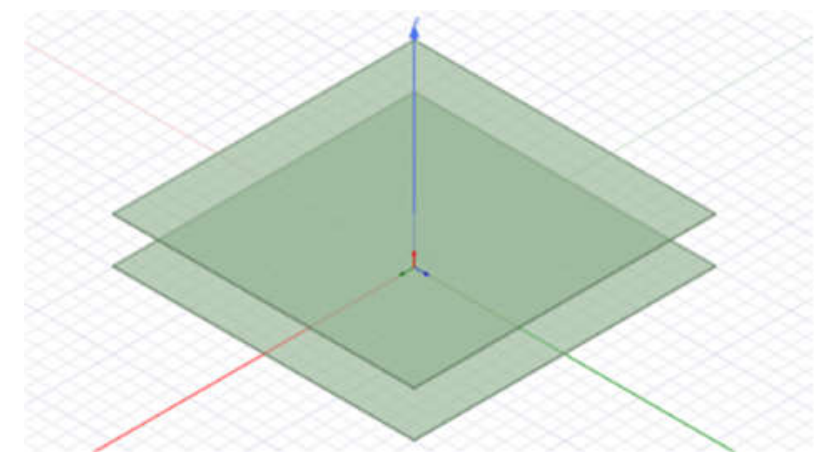

Fig. 1. Square parallel plate capacitor (PP-Cap) for capacitive power transfer.

Capacitive coupling is another wireless power transfer method that use parallel plate capacitors and electric fields as wireless power transfer medium. Researchers has demonstrated that up to $2.4 \mathrm{~kW}$ can be transferred by capacitive coupling with two $610 \mathrm{~mm} \times 610 \mathrm{~mm}$ parallel plate capacitors $(36.7 \mathrm{pF})$ separated by a distance of $150 \mathrm{~mm}$, as shown in Fig. 1[7].

The same team has also evaluated the possibilities of using capacitive coupling for dynamic wireless power transfer, where the primary side capacitor plates are extended as long tracks [8]. Siqi Li et.al also studied the possibilities of using dynamic capacitive power transferring technology in railway application[9]. Compared with inductive coupling, the capacitive coupled dynamic wireless power transfer does not cause eddy current loss in nearby metal objects and it also has a simpler coupler (metal plates only).

While the capacitive coupling is proved feasible in terms of dynamic power transfer ability, the long capacitor tracks can also be problematic in practical operation considering the cost of burying these wide capacitor plates into existing roads.

To reduce the cost of dynamic capacitive power transfer system, a novel Strip-Coupler is proposed in this paper. The primary capacitor plate is shrunk to a single wire and the secondary capacitor plate is extended along the driving direction to keep the coupling capacitance. The structure of the Strip-Coupler as well as the dynamic wireless power transfer system based on this coupler is explained. The design method of the strip-coupler based system is given. An additional advantage of the strip-coupler is that it is less sensitive to the lateral misalignment compared with square capacitor plate solution. 


\section{STRIP-COUPLER FOR DYNAMIC CPT}

To explain the design considerations of the proposed StripCoupler, some calculations about the amount of aluminum needed each kilometer is calculated based on [7]. The capacitor plates in [7] are made by square aluminum plates with $610 \mathrm{~mm}$ side length and $2 \mathrm{~mm}$ thickness. If these primary side capacitor plates are extended along the road to be a track, $2.44 \mathrm{~m}^{3}$ aluminum is needed for each kilometer. If the width of the capacitor plates are halved, the aluminum per kilometer can also be halved to $1.22 \mathrm{~m}^{3} / \mathrm{km}$. In an extreme case, the primary side is shrunk to a round cable with radius of $5 \mathrm{~mm}$, the aluminum needed can be reduced to $0.0785 \mathrm{~m}^{3} / \mathrm{km}$, only $3.2 \%$ of $2.44 \mathrm{~m}^{3}$.

The shrinking of primary side capacitor plate is also benefit for reducing the installation cost. According to [6], the installation cost of a $617 \mathrm{~m}$ long inductive track is as high as $\$ 658614$. Considering most of the highways have already been constructed, burying a long plate shape track with width $610 \mathrm{~mm}$ means the same width on the highway need to be cut out and reconstructed. For a round cable-shape primary side, only a gap with the diameter of the cable is needed, which is obviously cost-effective in terms of installation.

However, the shrinking of the primary capacitor plates will unavoidably reduce the coupling capacitance between the primary track and the receiver. To compensate this, the length $l$ of the receiver side capacitor plates are extended along the driving direction from $610 \mathrm{~mm}$ to $4000 \mathrm{~mm}$, considering the average length of a car is about $4500 \mathrm{~mm}$. The capacitance comparison will be given in the next section. Since the secondary capacitors do not need to be extended along the road but only mounted under car, the width of the capacitor plates can be as wide as possible with the only limit be the width of a car.

The detailed structure of the proposed Strip-Coupler is shown in Fig. 2. It consists of a long track and a receiver side capacitor plate. The track can be made by standard power cable. The receiver side capacitor plate is a rectangular metal plate with width $w$ and length $l$. the air gap distance between track and receiver plate is $d$. The installation of Strip-Coupler on a typical electrical vehicle is illustrated in Fig.3, where two tracks are buried into the road and two capacitor plates are mounted under the chassis of electric vehicle. Two coupling capacitors $C_{1}$ and $C_{2}$ are formed between tracks and the electric vehicle. The tracks are separated into many segments $(1-5 \mathrm{~km}$ each segment) and powered by different power supplies along the road, as shown in Fig. 4.

\section{STRIP-COUPLER DESIGN AND SIMULATION}

To design the Strip-Coupler, the width $w$, air gap distance $d$ and lateral misalignment are controlled separately to evaluate their influence to the coupling capacitance.

The capacitance between two parallel wires can be calculated by

$$
\mathrm{C}_{\mathrm{w} 2 \mathrm{w}}=\frac{\pi l \varepsilon_{0} \varepsilon_{r}}{\ln \left(\frac{d}{r}\right)},
$$

where $r$ is the diameter of the wire, $d$ is the distance between the two wire and $l$ is the length of the wire.

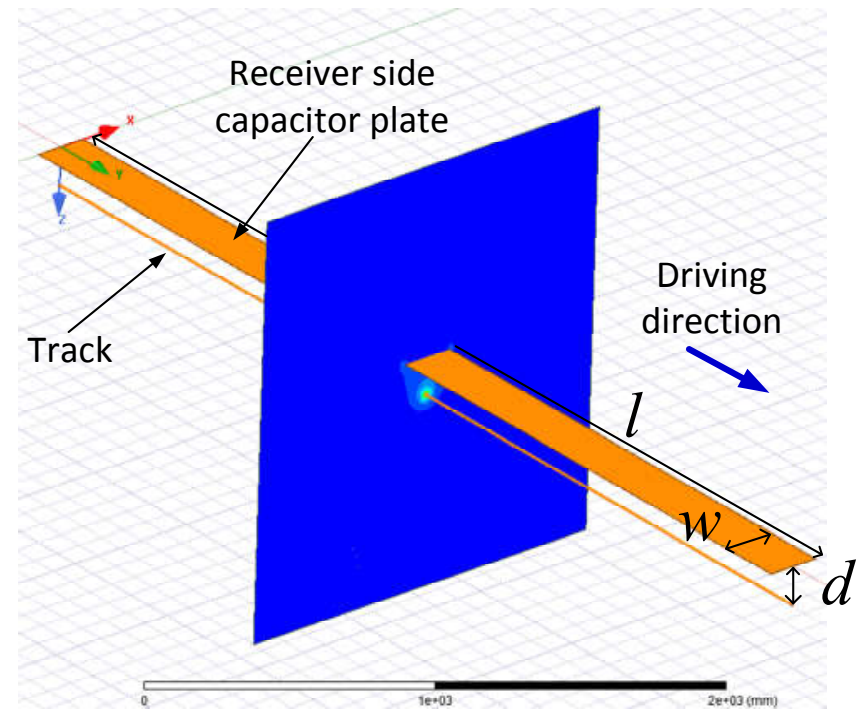

Fig. 2. Structure of Strip-Coupler.

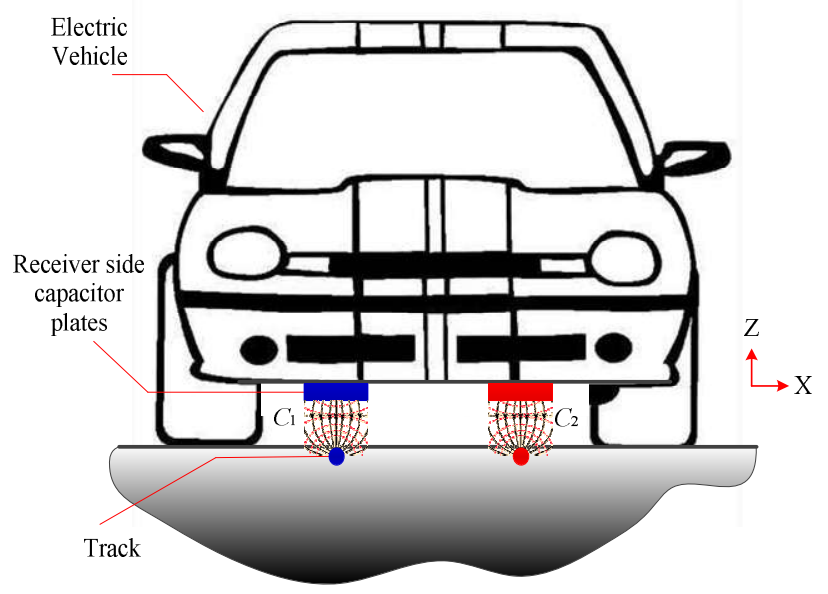

Fig. 3. Installation of Strip-Coupler.

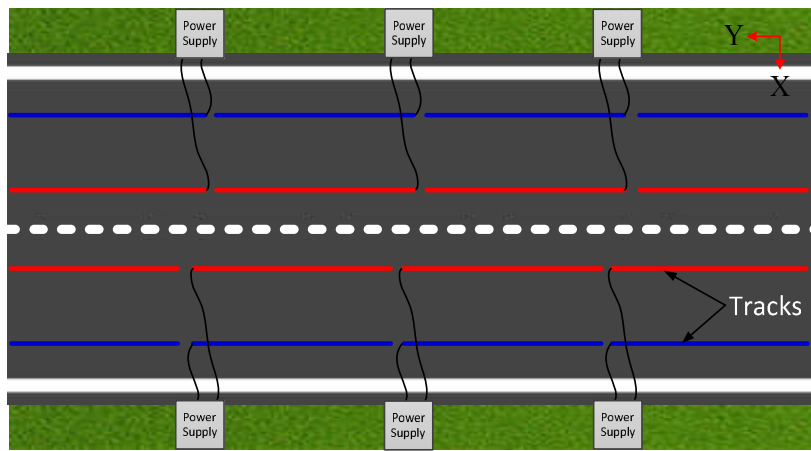

Fig. 4. Tracks of Strip-Coupler on highway.

The proposed Strip-Coupler is essentially a wire to plate capacitor, and its capacitance can be calculated by mirror method. The capacitance between wire and plate is two times the capacitance between the wire and its mirror with respect to the plate. Therefore, the wire to plate capacitor can be written as 


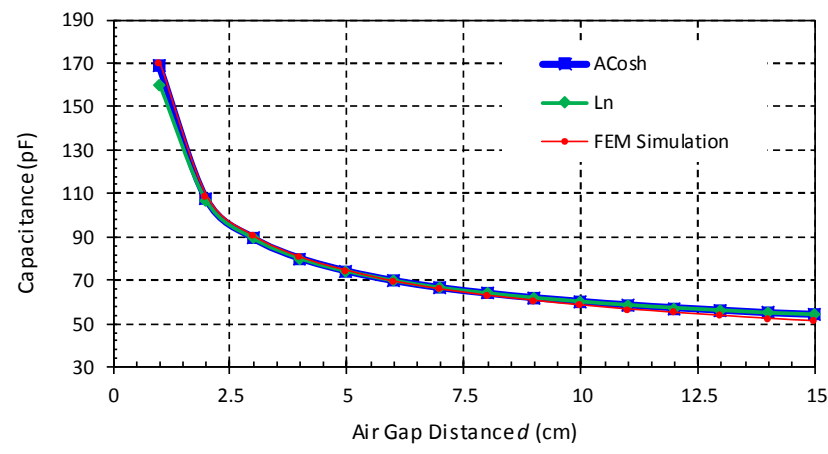

Fig. 5. Calculation and FEM simulation of the coupling capacitance of Strip-Coupler $(l=4000 \mathrm{~mm}, d=150 \mathrm{~mm}, w=300 \mathrm{~mm}, r=5 \mathrm{~mm})$.

$$
\mathrm{C}_{\mathrm{w} 2 \mathrm{p}}=\frac{2 \pi l \varepsilon_{0} \varepsilon_{r}}{\ln \left(\frac{2 d}{r}\right)},
$$

Using (2), the calculated capacitance over air gap distance is shown in Fig. 5.

There is another equation to calculate the wire to plate capacitance[10],

$$
\mathrm{C}_{\mathrm{w} 2 \mathrm{p}}=\frac{2 \pi l \varepsilon_{0} \varepsilon_{r}}{\cosh ^{-1}\left(\frac{2 d}{r}\right)} .
$$

The calculation results of (2) and (3) are shown in Fig. 5, where ACosh indicates the calculation results of (3) and Ln indicates the calculation results from (2). The calculation result of (3) with $10 \mathrm{~mm}$ air gap distance is $168.89 \mathrm{pF}$ while that of (2) is $160.44 \mathrm{pF}$. When the air gap distance is larger than $20 \mathrm{~mm}$, the two calculation results are almost the same. Note that both (2) and (3) assumes that the plate has infinite width $w$. To visualize the electric field between the track and the plate, a FEM simulation model has been built and simulated. The $l$ is set as $4000 \mathrm{~mm}, w$ is $300 \mathrm{~mm}$, and $d$ varies from $10 \mathrm{~mm}$ to $150 \mathrm{~mm}$, the simulation results is also shown in Fig.5. It can be found that the simulation results agree well with the two calculation results given by (2) and (3). When the $d$ is $10 \mathrm{~mm}$, the capacitance is $40.09 \mathrm{pF} / \mathrm{m}$, the capacitance drops as the distance increases nearly in the form of a logarithmic function, as described in (2). When the distance is larger than $50 \mathrm{~mm}$, the capacitance drops slowly with distance, from $18.6 \mathrm{pF} / \mathrm{m}$ to $12.8 \mathrm{pF} / \mathrm{m}$ when $d$ is increased from $50 \mathrm{~mm}$ to $150 \mathrm{~mm}$.

We have also evaluated the influence of the width of the receiver side capacitor plate over the coupling capacitance. As described in section II, the primary side track is restricted to a single wire, while the receiver side capacitor plate can be designed larger to give better misalignment performance and larger coupling capacitance without dramatically increasing the cost. As shown in Fig. 6 and Fig. 7, the air gap distance $d$ is fixed as $150 \mathrm{~mm}$ and length $l$ is set as $4000 \mathrm{~mm}$, and the width $w$ is varied from $100 \mathrm{~mm}$ to $1000 \mathrm{~mm}$ to see the coupling capacitance variation. When the width $w$ is $100 \mathrm{~mm}$, the coupling capacitance is $43.56 \mathrm{pF}$ and it increase as the width increases. But the increasing rate tends to be saturated when the width is larger than $500 \mathrm{~mm}$, which means increasing the width cannot always led to a increase of coupling capacitance. Fig. 6 gives the simulated electric fields between the track and

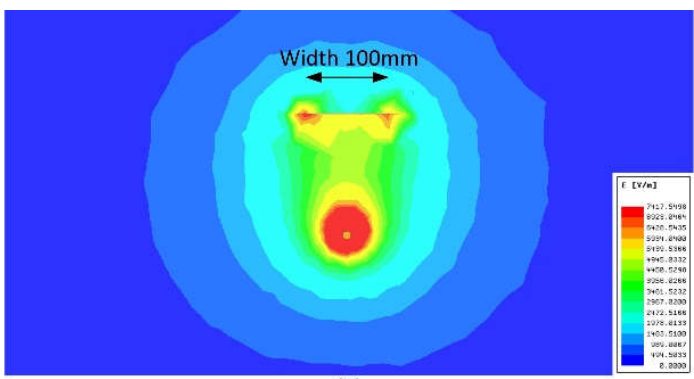

(a)
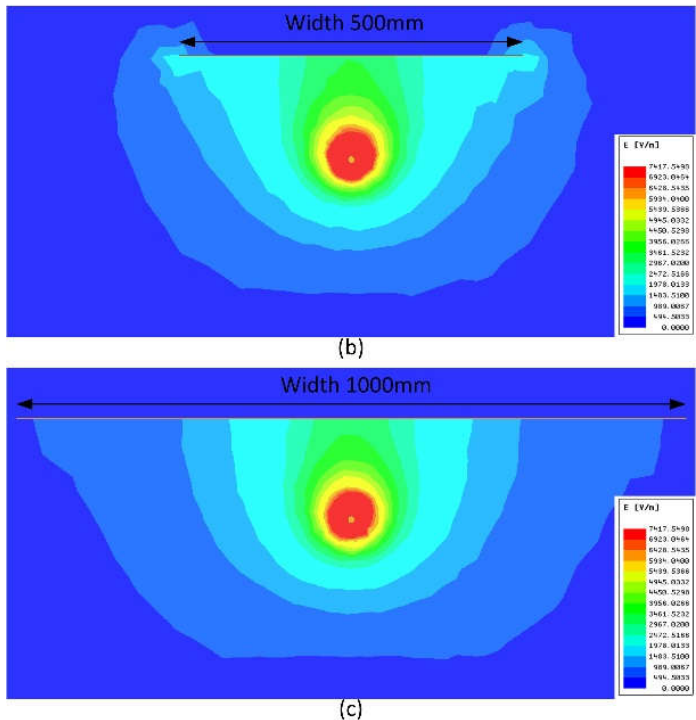

(c)

Fig. 6. Electric field comparision of the Strip-Coupler with different width $w$ (a) $w=100 \mathrm{~mm}$, (b) $w=500 \mathrm{~mm}$, (c) $w=1000 \mathrm{~mm}(l=4000 \mathrm{~mm}, d=150 \mathrm{~mm})$.

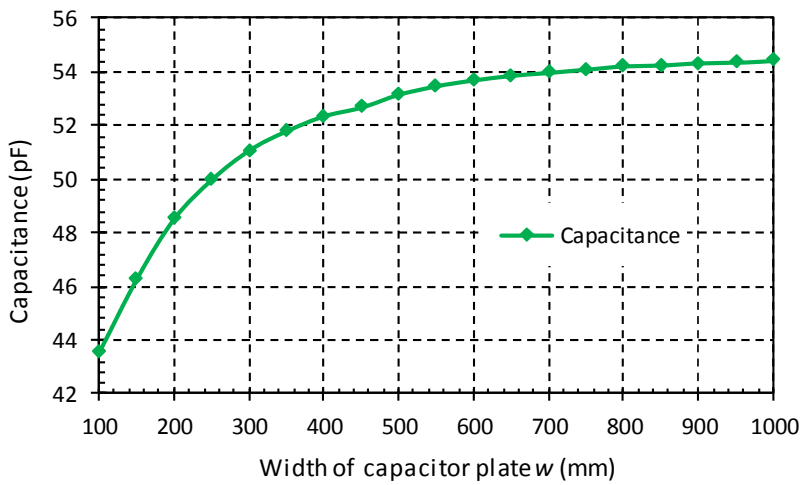

Fig. 7. Capacitance of Strip-Coupler with different width $(l=4000 \mathrm{~mm}$, $d=150 \mathrm{~mm}, w$ from $100 \mathrm{~mm}$ to $1000 \mathrm{~mm}$ ).

capacitor plates when the width is (a) $100 \mathrm{~mm}$, (b) $500 \mathrm{~mm}$ and (c) $1000 \mathrm{~mm}$ respectively. Comparing Fig. 6(a) to (c), we can found that although increasing the width can not always increasing the coupling capacitance, it can however be beneficial to shielding the electric field. Strong electric field (over $1500 \mathrm{~V} / \mathrm{m}$ ) can be found at the upper side of the receiver capacitor plate in Fig. 6(a), which only exists around the edge of the capacitor plates in Fig. 6(b). For Fig. 6(c), however, there is almost no electric field at the upper side and edge of the capacitor plate. 
The electric field distribution of the Strip-Coupler with different misalignment is shown in Fig. 8. When there is no

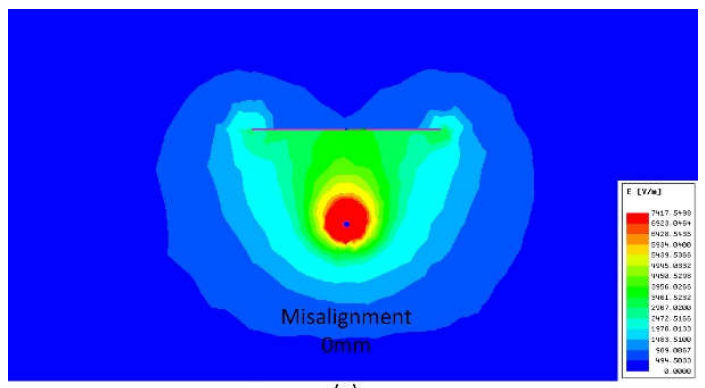

(a)

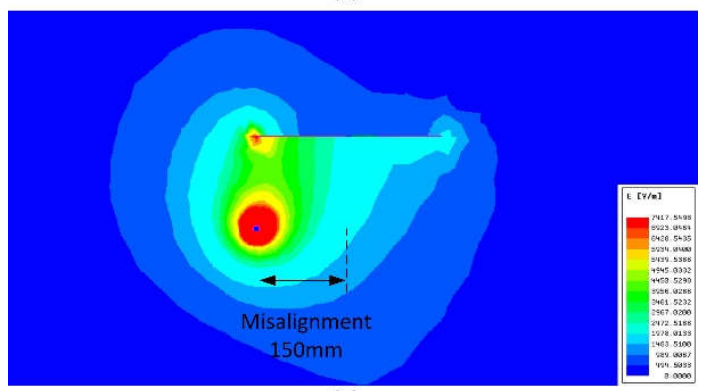

(b)

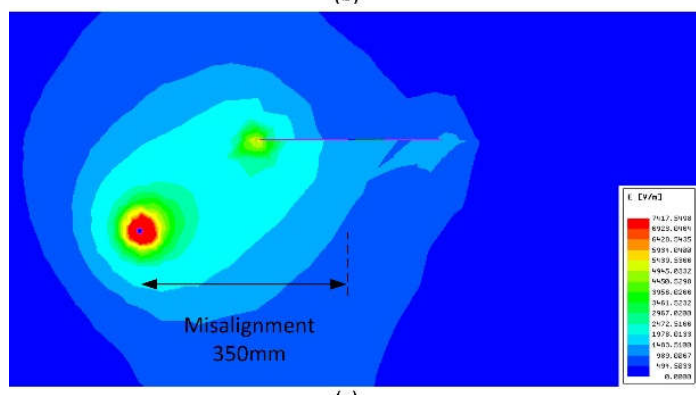

(c)

Fig. 8. FEM simulation of Strip-Coupler under different misalignment (a) without misalignment, (b) $150 \mathrm{~mm}$ misalignment and (c) $350 \mathrm{~mm}$ misalignment.

misalignment, it can be found that the electric field is symmetrical to the line between the track and the center of the capacitor plate. The field around the track is strongest and decrease as the distance increases. When misalignment happens, the electric field misaligns accordingly, and stronger electric field can be observed around the edge that is closer to the misaligned track.

As benchmark, the electric field and misalignment performance of the square parallel plate capacitor (PP-Cap) shown in Fig. 1 is also simulated as shown in Fig. 9. The side length of the square PP-Cap is $720 \mathrm{~mm}$, which gives a $51.77 \mathrm{pF}$ coupling capacitance at zero misalignment. The air gap distance is also set as $150 \mathrm{~mm}$. From Fig. 9 (a) to (c) we can found that the electric field also deform with misalignment. Comparing Fig. 8 and Fig. 9, the red area is the area with field strength larger than $7417 \mathrm{~V} / \mathrm{m}$, and it's obvious that the red area of the PP-Cap is much larger than the proposed StripCoupler.

Fig. 10 gives the simulated capacitance variation of both the Strip-Coupler and the PP-Cap under different misalignment from $-350 \mathrm{~mm}$ to $350 \mathrm{~mm}$. Two cases of the Strip-Coupler with width of the receiver side capacitor plate being $300 \mathrm{~mm}$ and $500 \mathrm{~mm}$ are adopted. The simulation result indicates that both the coupling capacitance of the PP-Cap and the Strip-Coupler drops with misalignment. For the PP-Cap,

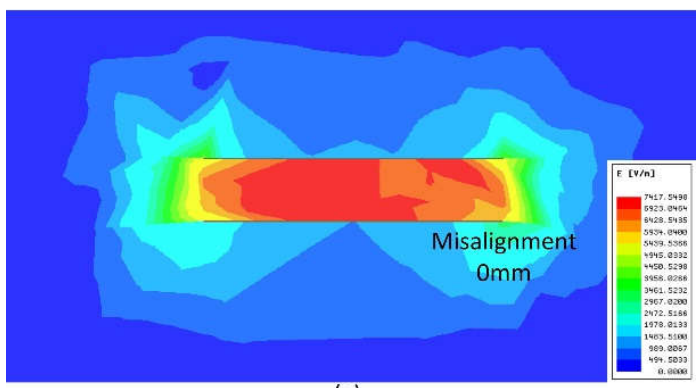

(a)

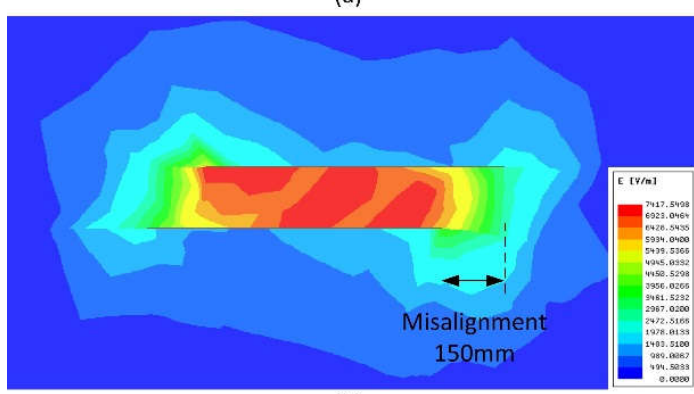

(b)

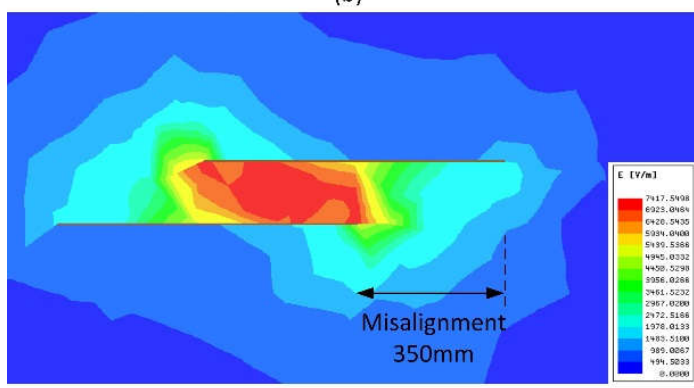

(c)

Fig. 9. FEM simulation of PP-Cap under different misalignment (a) without misalignment, (b) $150 \mathrm{~mm}$ misalignment and (c) $350 \mathrm{~mm}$ misalignment.

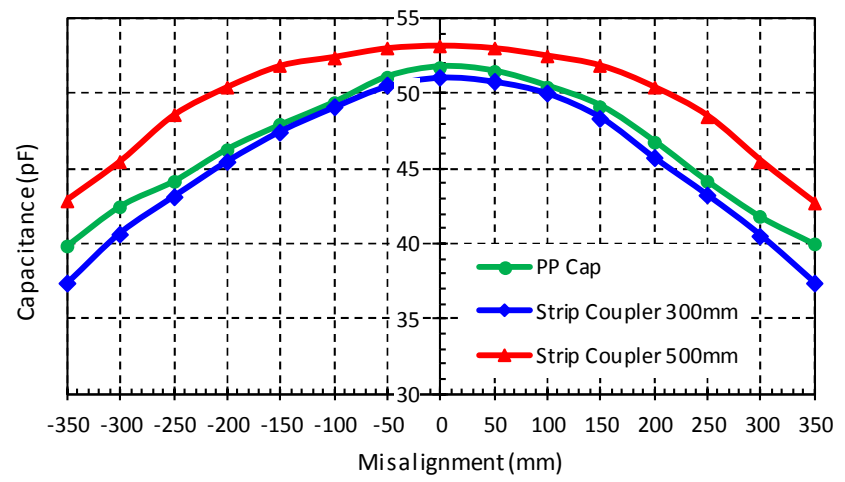

Fig. 10. Misalignemnt performance of Strip-Coupler compared with square capacitor (for Strip-Coupler, $l=4000 \mathrm{~mm}, w=300 \mathrm{~mm}$ and $500 \mathrm{~mm}, d=150 \mathrm{~mm}$; for square capacitor, side length $=500 \mathrm{~mm}, d=150 \mathrm{~mm}$ ).

coupling capacitance drops to $39.9 \mathrm{pF}$ at $350 \mathrm{~mm}$ misalignment, which is $77.07 \%$ of the starting capacitance without misalignment. For the Strip-Coupler with $300 \mathrm{~mm}$ receiver side capacitor plate width, the capacitance drops to $73.09 \%$ of the starting capacitance to $37.33 \mathrm{pF}$, which is worse than the PP-Cap in terms of misalignment performance. For the StripCoupler with $500 \mathrm{~mm}$ width, however, the coupling 
capacitance only drops $19.3 \%$, from $53.15 \mathrm{pF}$ to $42.91 \mathrm{pF}$. Therefore, with proper chosen of receiver side capacitance

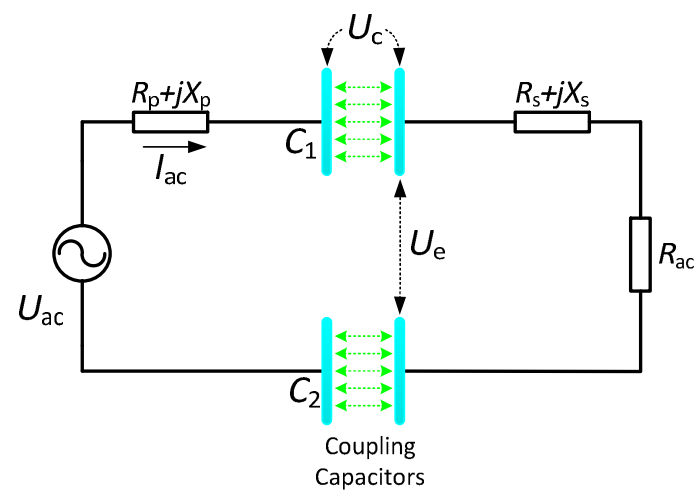

Fig. 11. Equivalent circuit of series compensated capacitive power transfer system.

\section{Maximum output power VS given voltage stress}

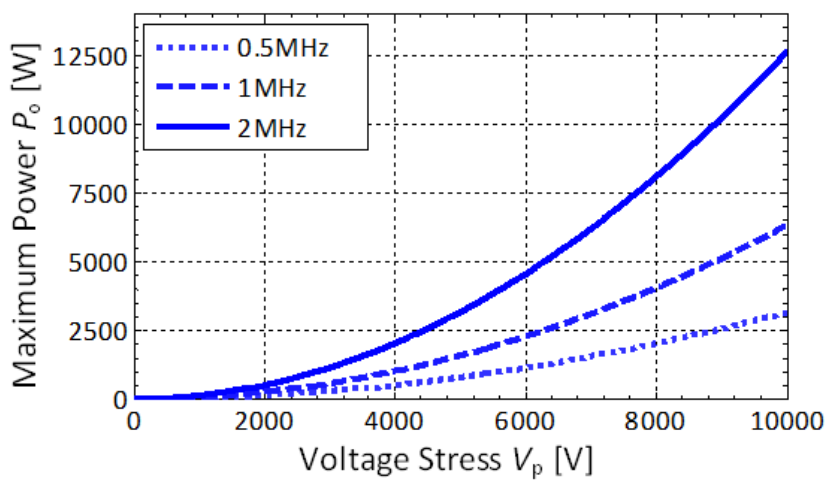

Fig. 12. Calculated power transfer ability of a capacitive power tranfer circuit with different resonant frequency and voltage stress on coupling capacitor.

\section{Maximum output power VS given voltage stress}

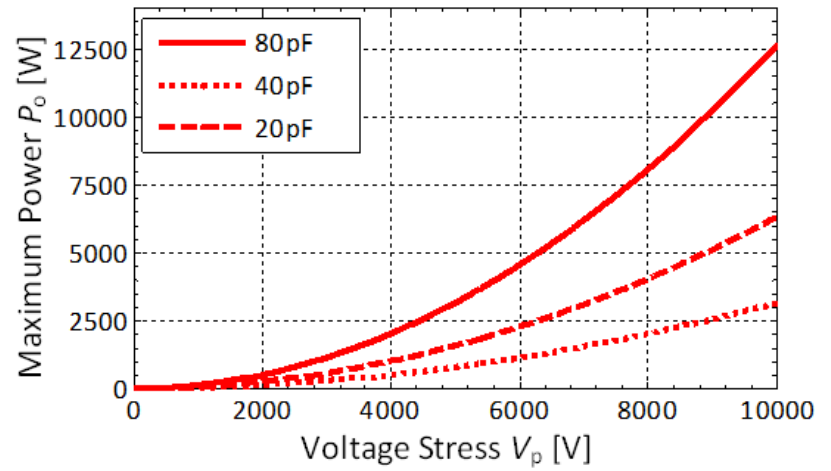

Fig. 13. Calculated power transfer ability of a capacitive power tranfer circuit with different coupling capacitance and voltage stress on coupling capacitors.

plate width, the proposed Strip-Coupler can have better misalignment performance than the conventional PP-Cap.

\section{Circuit Desigen and CAlculation}

The simplest series compensated single phase capacitive power transfer topology is shown as Fig. 11 . The $C_{1}$ and $C_{2}$ are the two coupling capacitors, which in this paper is formed by two Strip-Coupler as described in the previous section. Using both fundamental approximation and Thevenin's Theorem, the primary inverter and compensation circuit can

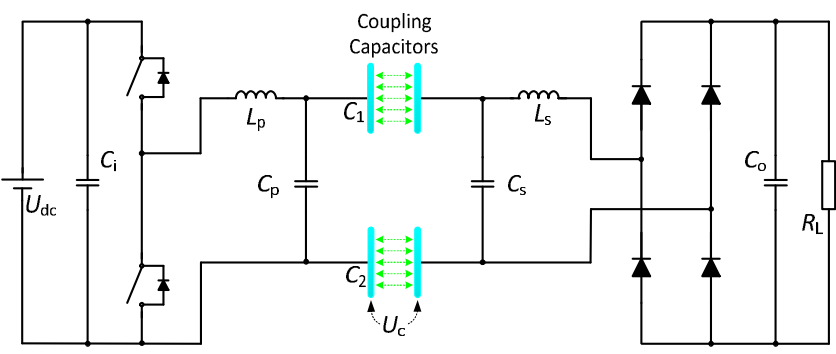

Fig. 14. Double-sided $L C$-compensation circuit for prototype.

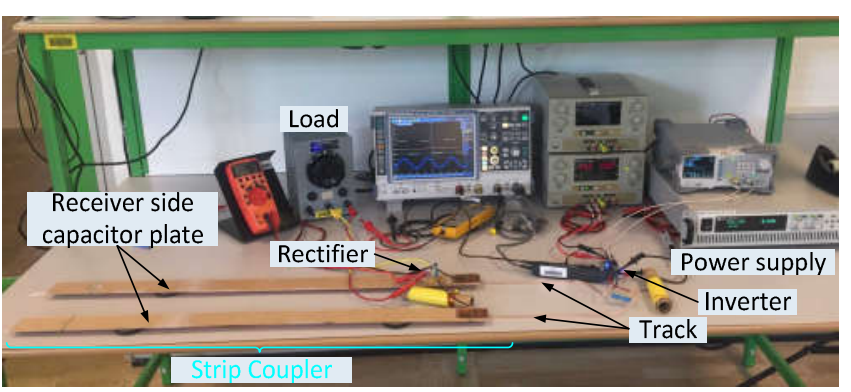

Fig. 15. Experimental testing setup.

be simplified as an ac voltage source $U_{\text {ac }}$ and an impedance $R_{\mathrm{p}}+j X_{\mathrm{p}}$. Similarly, the load and secondary compensation circuit can be simplified as an equivalent ac load $R_{\mathrm{ac}}$ in series with an impedance $R_{\mathrm{s}}+j X_{\mathrm{s}} . R_{\mathrm{p}}$ and $R_{\mathrm{s}}$ represent the equivalent lossy parasitic components such as the inner resistance of inverter and equivalent series resistance (ESR) of resonant inductor, ESR of resonant inductor on the primary and secondary sides, respectively. To minimize the input voltage, here $X_{\mathrm{p}}$ and $X_{\mathrm{s}}$ are designed in resonance with $C_{1}$ and $C_{2}$.

$$
\left(X_{\mathrm{p}}+X_{\mathrm{s}}\right)=\frac{1}{\omega C}, C=\frac{C_{1} C_{2}}{C_{1}+C_{2}},
$$

where $\omega$ is the resonant angular frequency. At the steady state, the CPT system in Fig. 11 can be described by following equations.

$$
\begin{aligned}
& U_{\mathrm{ac}}=\left(R_{\mathrm{p}}+R_{\mathrm{s}}+R_{\mathrm{ac}}\right) \sqrt{P_{\mathrm{o}} / R_{\mathrm{ac}}} \\
& I_{\mathrm{ac}}=U_{\mathrm{ac}} /\left(R_{\mathrm{p}}+R_{\mathrm{s}}+R_{\mathrm{ac}}\right)
\end{aligned}
$$

The voltage on coupling capacitor is

$$
U_{\mathrm{c}}=\frac{1}{2 \omega C} \sqrt{\frac{P_{\mathrm{o}}}{R_{\mathrm{ac}}}}
$$

For a single phase capacitive power transfer circuit, the power transferred to the receiver side can thus be written as

$$
P_{\mathrm{o}}=4 \omega^{2} C^{2} R_{a c} U_{\mathrm{c}}^{2}
$$

Fig. 12 and Fig. 13 gives the calculated output power as a function of voltage stress on coupling capacitors with different switching frequency and coupling capacitors. It can be found that a high voltage is necessary to ensure a high transferred power given that the coupling capacitor is less than $100 \mathrm{pF}$. This is also one of the main concerns of capacitive power transfer system in real application. 
Nevertheless, Fig. 12, Fig. 13 and Eq. (8) also indicates that the power transfer ability of a capacitive power transfer system is unlimited even if the coupling capacitance is picofarad level. For a given output power, the voltage stress can be reduced by increasing the

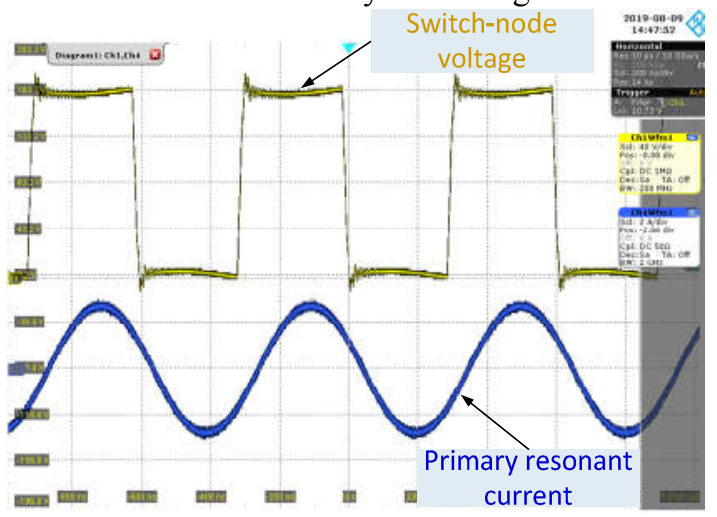

Fig. 16. Primary side voltage and current waveforms.

TABLE I. SYSTEM SPECIFICATIONS AND CiRCUIT PARAMETERS

\begin{tabular}{cccc}
\hline \hline Symbol & Value & Symbol & Value \\
\hline$V_{\text {in }}$ & $165 \mathrm{~V}$ & $L_{\mathrm{p}} / L_{\mathrm{s}}$ & $32.4 \mu \mathrm{H}$ \\
$V_{\text {out }}$ & $30 \mathrm{~V}$ & $C_{\mathrm{p}} / C_{\mathrm{s}}$ & $220 \mathrm{pF}$ \\
$f_{\text {sw }}$ & $1.64 \mathrm{MHz}$ & $C_{1} / C_{2}$ & $9.5 \mathrm{pF}$ \\
$P_{\mathrm{o}}$ & $20 \mathrm{~W}$ & $R_{\mathrm{L}}$ & $45 \Omega$ \\
\hline \hline
\end{tabular}

coupling capacitance, increasing the switching frequency or increasing the equivalent load resistance $R_{\mathrm{ac}}$.

\section{EXPERIMENT RESULTS}

To validate the proposed Strip-Coupler, A scaled-down prototype has been built and tested. The parameters of the prototype is listed in Table I. To compensate the high impedance of the coupling capacitors, LC-compensation circuit are used at both primary and secondary side. From another point of view, the primary LC-compensation circuit steps-up the input voltage and the secondary LCcompensation circuit steps-down the voltage after the coupling capacitors. The experimental testing setup is shown in Fig. 15, where the length $l$ of the receiver side capacitor plate is $800 \mathrm{~mm}$, width $w$ is $50 \mathrm{~mm}$. The primary track is made by copper wire with a diameter of $3 \mathrm{~mm}$, and the air gap distance $d$ between the track and the receiver side capacitor plate is $10 \mathrm{~mm}$. The measured coupling capacitance between each track and plate is $9.5 \mathrm{pF}$ at $1.64 \mathrm{MHz}$, which yields a series coupling capacitance of $\sim 4.75 \mathrm{pF}$.

Fig. 16 shows the measured waveforms from the testing setup, i.e. the primary side switch-node voltage and resonant current waveforms. The measured waveforms in Fig. 16 indicate the transistors are soft switching, and the switch voltage overshoot is $\sim 14.5 \mathrm{~V} \quad(\sim 8.8 \%$ of input voltage). Although the power loss of the primary inverter is effectively controlled, the system efficiency is, however, only $\sim 25.5 \%$ because of the high reactive current in the primary LCcompensation circuit. The primary resonant inductor $L_{\mathrm{p}}$ is about $80^{\circ} \mathrm{C}$ at $20 \mathrm{~W}$ output. An LC-compensation circuit with higher $Q$-value or a multiple stage higher order compensation circuit is expected to be able to reduce the reactive current loss at the primary side. This will be further evaluated in the future research.

\section{CONCLUSION}

A novel Strip-Coupler is proposed in this paper for dynamic capacitive power transfer application. The electric fields around the coupler and its capacitance has been evaluated through FEM simulation. Several parameters that affecting the design of the strip-coupler is also researched. The proposed Strip-Coupler can dramatically reduce the cost of a dynamic wireless power transfer system, which is one of the main obstacles preventing this technology from been used. The Strip-Coupler is also not sensitive to the lateral misalignment, which makes the charging system robust. The power transfer ability of the proposed Strip-Coupler is demonstrated with a scaled-down prototype, and about $20 \mathrm{~W}$ is wirelessly transferred to a $45 \Omega$ load with only $\sim 4.75 \mathrm{pF}$ coupling capacitance.

\section{REFERENCES}

[1] Z. Rezvani, J. Jansson, J. Bodin, "Advances in consumer electric vehicle adoption research: A review and research agenda," Transportation research part D: transport and environment. Vol. 34, pp. 122-136, 2015.

[2] S. J. Huang, T. S. Lee, W. H. Li, R. Y. Chen, "Modular On-Road AGV Wireless Charging Systems Via Interoperable Power Adjustment," IEEE Trans. Ind. Electron., vol. 66, no. 8, pp. 5918 - 5928, Aug. 2019.

[3] G. A. Covic, J. T. Boys, "Inductive Power Transfer," Proceedings of the IEEE. Vol. 101, No. 6, pp. 1276-1289, June, 2013.

[4] J. M. Miller, P. T. Jones, J. M. Li, O. C. Onar, "ORNL experience and challenges facing dynamic wireless power charging of EV's," IEEE Circuits and Systems Magazine. Vol. 15, No. 2, pp. 40-53, 2015.

[5] C. C. Mi, G. Buja, S. Y. Choi, C. T. Rim, "Modern advances in wireless power transfer systems for roadway powered electric vehicles," IEEE Trans. Ind. Electron. Vol. 63, No. 10, pp. 6533-6545, 2016.

[6] S. Jeong, Y. J. Jang, and D. Kum, "Economic analysis of the dynamic charging electric vehicle,” IEEE Trans. Power Electron., vol. 30, no. 11, pp. 6368-6377, Nov. 2015.

[7] F. Lu, H. Zhang, H. Hofmann, C. Mi, "A double-sided lclc compensated capacitive power transfer system for electric vehicle charging," IEEE Trans Power Electron, vol. 30, no. 11, pp. 6011-6014, 2015.

[8] F. Lu, H. Zhang, H. Hofmann, M. Ying, C. Mi, “A Dynamic Capacitive Power Transfer System with Reduced Power Pulsation," Proceedings of the IEEE PELS Workshop on Emerging Technologies: Wireless Power Transfer (WoW). pp. 60-64, Oct. 2016.

[9] S. Li, Zhe Liu, H. Zhao, L. Zhu, C. Shuai, and Z. Chen, "Wireless power transfer by electric field resonance and its application in dynamic charging," IEEE Trans. Ind. Electron., vol. 63, no. 10, pp. 6602-6612, Oct. 2016.

[10] Paul, C. R. Analysis of multiconductor transmission lines. John Wiley \& Sons, 2008 